\title{
Apremilast: A new hope in psoriasis
}

\author{
Sachin Agarwal ${ }^{1}$, Amarjeet Singh Verma ${ }^{2, *}$, Prashant Kumar Yadav ${ }^{3}$, Megha Sharma $^{4}$, Harmeet Kaur \\ ${ }^{1}$ Associate Professor, ${ }^{2}$ Assistant Professor ${ }^{3,5}$ PG Resident, ${ }^{4}$ Senior Resident, Dept. of Skin \& VD, Saraswathi Institute of Medical \\ Sciences, Hapur, Uttar Pradesh, India
}

*Corresponding Author:

Email: amarjeetverma.av@gmail.com

\begin{abstract}
Introduction: Psoriasis is a common, chronic, inflammatory skin disease that can have a significant impact on the quality of life of those who are afflicted due to chronicity of the disease and frequent remissions and relapse. There is a vast array of drugs for the treatment. Methotrexate, cyclosporine and retinoids are the most commonly used conventional systemic drugs. Newer studies provide insight into their more effective and safer use and as combination therapy with biologics. Apremilast is an orally administered, small molecule inhibitor of phosphodiesterase 4 (PDE4). Apremilast $30 \mathrm{mg}$ twice daily reduced the severity of moderate to severe plaque psoriasis, palmoplantar psoriasis and guttate psoriasis.

Objective: To evaluate efficacy, tolerability and adverse effects of apremilast.

Materials and Methods: A clinical trail was conducted in department of Skin \& VD of Saraswathi institute of medical college on 80 patients. Apremilast was started after initial titration and followed for 8 weeks.

Results: Out of 80 patients 73 patients completed the study of which $69 \%$ patients have responded well and $14 \%$ patient did not show satisfactory result. No major side effect encountered during the study.

Conclusion: Apremilast was effective in plaque psoriasis, palmo plantar psoriasis and guttate psoriasis and is well tolerated with mild adverse effects. Also the regular lab investigations as required in others systemic treatment modalities are avoided.
\end{abstract}

Keywords: Apremilast, Plaque psoriasis, Phosphodiesterase 4 (PDE4), Guttate psoriasis, Palmo plantar psoriasis.

\section{Introduction}

Psoriasis is a chronic inflammatory cutaneous disorder, affecting up to $2 \%-5 \%$ of the world population. Owing to the chronic course displayed in this condition, long-term treatment is necessitated. Traditionally, drugs employed in this setting, such as methotrexate (Mtx), cyclosporine A (CsA), and azathioprine (Azt), are associated with serious adverse effects and warrant proper monitoring throughout the treatment. Biologic therapies, on the other hand, though effective have their own disadvantages related to treatment resistance, hospital admission, parenteral administration, adverse effect profile, expenses and management requiring a specialist setting. Therefore, there is an ongoing research for the discovery of an ideal drug for managing psoriasis. Apremilast is a small orally available molecule that has demonstrated its worth for the same. Apremilast directly targets the central initiator mechanism in the pathogenesis of psoriasis, and in this way modulates the expression of various inflammatory mediators involved in this process. Post intake, it is rapidly absorbed by the body reaching its peak plasma concentration after 2-3 h. The bioavailability of apremilast is around $73 \%$ and its mean apparent volume of distribution is $87 \mathrm{~L}$. Apremilast has a $t_{1 / 2}$ of 6-9 h. Metabolism of apremilast occurs through a cytochrome (CYP) 3A4mediated oxidative metabolism, followed by glucuronidation, nonenzymatic hydrolysis, and a nonCYP 3A4-mediated metabolism. Apremilast is eliminated mainly by the renal route, though some of the drug is also excreted through the feces.

\section{Materials and Methods}

A clinical trial was conducted in department of Skin \& VD of Saraswathi institute of medical college on 80 patients. Inclusion criteria comprised of all patient $>18$ years of age of both sexes and have not received any treatment for 3 months. Three types of psoriasis patients are taken for study viz plaque, palmoplantar and guttate psoriasis. Number of patient in each type of psoriasis are shown in table 1

\section{Table 1}

\begin{tabular}{|l|c|}
\hline \multicolumn{1}{|c|}{ Type of psoriasis } & Numbers \\
\hline Plaque psoriasis & 39 \\
\hline Palmo plantar psoriasis & 17 \\
\hline Guttate psoriasis & 24 \\
\hline Total & 80 \\
\hline
\end{tabular}

Exclusion criteria includes pregnant, lactating women and immunosuppressed patients. Apremilast was started with the dose of $30 \mathrm{mg}$ twice a day after initial titration and followed for 8 weeks for safety, tolerability and adverse effect.

Improvement in the lesions is followed clinically and on serial photography for eight weeks as poor (0$25 \%$ improvement), good (25-50\% improvement), very good (50-75\% improvement) and excellent (>75\% improvement) response.

\section{Results}

Out of 80 patients 73 patients completed the study out of which 23 patients presented with excellent 
response, 21 patients with very good response, 19 with good response, however 10 patient did not shown any satisfactory improvement. Out of total patients who complete the study 26 presented with few side effects in the form of nausea, vomiting, headache, diarrhea etc. Most common side effect being nausea and vomiting which predominantly presented in first week of start of treatment. However most side effects were mild or moderate in severity and did not lead to discontinuation of treatment.

Table 2

\begin{tabular}{|l|c|}
\hline Response Grading & $\begin{array}{c}\text { Number of } \\
\text { Patients }\end{array}$ \\
\hline Poor /no response $(0-25 \%)$ & 10 \\
\hline Good response $(25-50 \%)$ & 19 \\
\hline Very good response $(50-75 \%)$ & 21 \\
\hline Excellent response $(>75 \%)$ & 23 \\
\hline
\end{tabular}

\section{Chart 1}

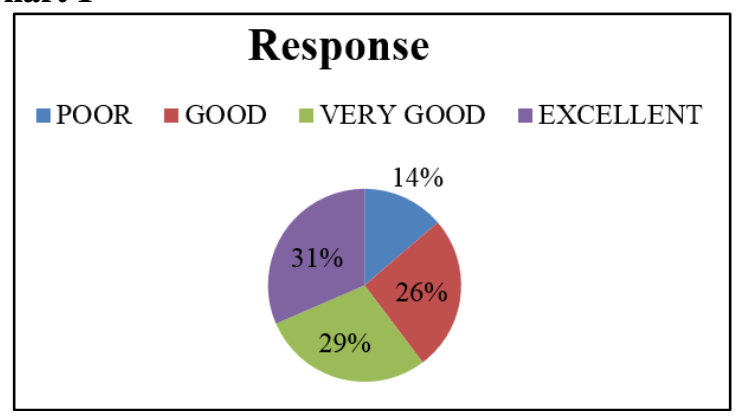

\section{Discussion}

Psoriasis is a chronic systemic inflammatory disease characterized by dysregulated immune responses, with an imbalance in the production of proinflammatory and anti inflammatory cytokines.
Palmoplantar plaque psoriasis is localized to the palms and/or soles and characterized by well-defined red, scaly plaques or thickening/ scaling without redness that may or may not include pustules. Palmoplantar plaque psoriasis is difficult to treat as shown by its varying responsiveness to treatments. Patients with plaque psoriasis and palmoplantar psoriasis have greater functional disability and decrements in healthrelated quality of life compared with patients with plaque psoriasis lesions located elsewhere on the body. Patients with palmoplantar psoriasis report greater impairment of mobility, self-care activities (i;e. usual activities) and greater dependency on topical medications.

Cyclic adenosine monophosphate, a key modulator of immune cell responses, is predominantly regulated by phosphodiesterase 4 (PDE4). Apremilast, an oral PDE4 inhibitor, works intracellularly to regulate inflammatory mediators, including pathways relevant to the pathogenesis of psoriasis. PDE4 inhibition elevates intracellular cyclic adenosine monophosphate, which in turn down-regulates the inflammatory responses within T helper (Th) 1, Th17, and type 1 interferon pathways and modulates production of anti-inflammatory cytokines, such as interleukin (IL)-10. Apremilast was approved by the US Food and Drug Administration (FDA) in 2014 and by the European Commission in 2015 for treatment of psoriasis and psoriatic arthritis. Apremilast is the first oral drug to receive FDA approval for psoriasis since 1996. It is recommended that apremilast be standardized to the recommended dose of $30 \mathrm{mg}$ twice daily, to be taken orally starting on day 6 . The recommended initial dosage of apremilast from day 1 to day 5 as shown in table 2 .

Table 2

\begin{tabular}{|c|c|c|c|c|c|c|c|c|c|c|}
\hline Day 1 & \multicolumn{2}{|c|}{ Day 2 } & \multicolumn{2}{c|}{ Day 3 } & \multicolumn{2}{c|}{ Day 4 } & \multicolumn{2}{c|}{ Day 5 } & \multicolumn{2}{c|}{ Day 6 and beyond } \\
\hline AM & AM & PM & AM & PM & AM & PM & AM & PM & AM & PM \\
\hline $10 \mathrm{mg}$ & $10 \mathrm{mg}$ & $10 \mathrm{mg}$ & $10 \mathrm{mg}$ & $20 \mathrm{mg}$ & $20 \mathrm{mg}$ & $20 \mathrm{mg}$ & $20 \mathrm{mg}$ & $30 \mathrm{mg}$ & $30 \mathrm{mg}$ & $30 \mathrm{mg}$ \\
\hline
\end{tabular}

After 8 week of treatment $31 \%$ of patients showed excellent response, $29 \%$ and $26 \%$ patient showed very good and good response respectively, while poor response was observed in $14 \%$.

During the study common side effects were seen in the form of nausea, vomiting, diarrhoea, upper respiratory infection, headache, weight loss and depression. Most common side effects were nausea, vomiting, diarrhoea which were mild to moderate in severity and resolved with continued therapy, without medicinal intervention. Highest frequency of side effects seen during the first 2 weeks of dosing and decreased thereafter.

Table 3

\begin{tabular}{|l|c|}
\hline \multicolumn{1}{|c|}{ Weeks } & Adverse effect \\
\hline $1^{\text {st }}$ week & 17 \\
\hline $2^{\text {nd }}$ week & 5 \\
\hline $3^{\text {rd }}$ week & 2 \\
\hline $4^{\text {th }}$ week & 1 \\
\hline
\end{tabular}




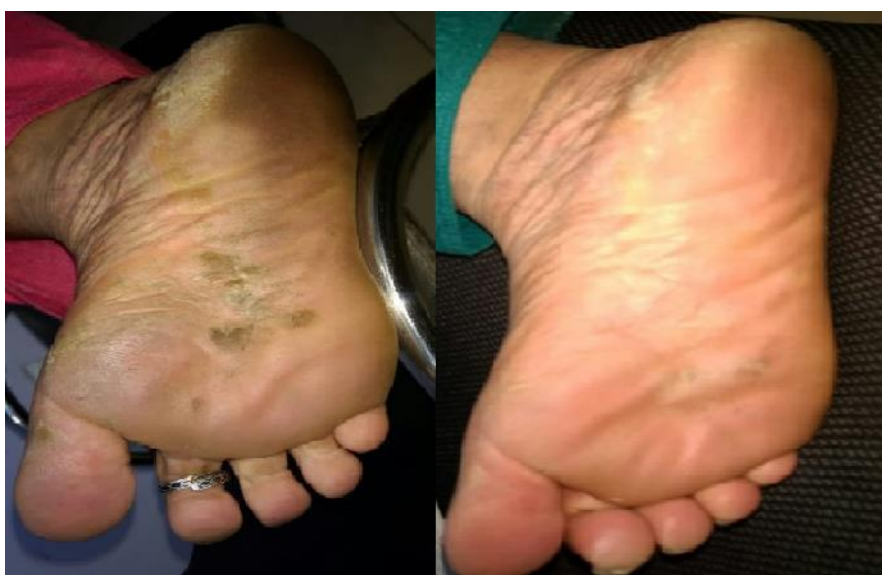

Fig. 1

This study demonstrated a significant therapeutic effect of apremilast $30 \mathrm{mg}$ twice daily on disease activity, including improvement in signs and symptoms of psoriasis with mild side effects.

\section{Conclusion}

Apremilast reduced the severity of plaque, guttate and palmoplantar psoriasis. Apremilast demonstrated an acceptable safety profile, effective and was generally well tolerated. Apremilast provides healthcare practitioners a therapeutic option with a favorable benefit: risk profile for patients. No pre-screening or ongoing laboratory monitoring is required.

\section{References}

1. Bubna AK. Apremilast: A dermatologic perspective. Indian J Drugs Dermatol. 2016;2:75-82.

2. Kanwar AJ, Yadav S, Dogra S. Psoriasis: What is new in nonbiologic systemic therapy in the era of biologics?. Indian J Dermatol Venereol Leprol. 2010;76:622-33.

3. Khandpur S, Bhari N. Newer targeted therapies in psoriasis. Indian J Dermatol Venereol Leprol. 2013;79, Suppl S1:47-52.

4. Houslay MD, Schafer P, Zhang KY. Keynote review: phosphodiesterase-4 as a therapeutic target. Drug Discov Today. 2005;10:1503-19.

5. Edwards CJ, Blanco FJ, Crowley J. Ann Rheum Dis Published Online First:10.1136/annrheumdis- 2015207963.

6. Menter A, Gottlieb A, Feldman SR. Guidelines of care for the management of psoriasis and psoriatic arthritis: Section 1. Overview of psoriasis and guidelines of care for the treatment of psoriasis with biologics. J Am Acad Dermatol. 2008;58:826-50.

7. Papp K, Reich K, Leonardi CL. Apremilast, an oral phosphodiesterase 4 (PDE4) inhibitor, in patients with moderate to severe plaque psoriasis: results of a phase III, randomized, controlled trial (Efficacy and Safety Trial Evaluating the Effects of Apremilast in Psoriasis [ESTEEM] 1). J Am Acad Dermatol. 2015;73(1):37-49.

8. Paul C, Cather J, Gooderham M. Efficacy and safety of apremilast, an oral phosphodiesterase 4inhibitor, in patients with moderateto- severe plaque psoriasis over 52 weeks, a phase III randomized controlled trial (ESTEEM 2). Br J Dermatol. 2015;173(6):1387-99.
9. Gisondi P, Girolomoni G. Apremilast in the therapy of moderate-to-severe chronic plaque psoriasis. Drug Des Devel Ther. 2016;10:1763-70.

10. Sobell JM, Foley P, Toth D, et al. Effects of apremilast on pruritus and skin discomfort/pain correlate with improvements in quality of life in patients with moderate to severe plaque psoriasis. Acta Derm Venereol. 2016;96(4):514-520.

11. Korman N, et al. Apremilast, an oral phosphodiesterase-4 inhibitor, in patients with moderate to severe plaque psoriasis: pooled 16-week efficacy in patient subgroups (ESTEEM 1 and 2). Poster presented at the 73rd annual meeting of the American Academy of Dermatology; San Francico, California; March 20-24, 2015.

12. Abraham BP, Shah K, MD; Levi E, Sellin J. Apremilast for the treatment of psoriasis and psoriaticarthritis: management of gastrointestinal adverse effects. Poster presented at the 74th Annual Meeting of the American Academy of Dermatology, Washington DC; March 4-8, 2016.

13. Gottlieb AB, Matheson RT, Menter A, et al. Efficacy, tolerability, and pharmacodynamics of apremilast in recalcitrant plaque psoriasis: a phase II open-label study. J Drugs Dermatol. 2013;12:888-97.

14. Brunasso AM, Puntoni M, Aberer W, Delfino C, Fancelli L, Massone C. Clinical and epidemiological comparison of patients affected by palmoplantar plaque psoriasis and palmoplantar pustulosis: a case series study. $\mathrm{Br} \mathrm{J}$ Dermatol. 2013;168:1243-51.

How to cite this article: Agarwal S, Verma AS, Yadav PK, Sharma M, Kaur H. Apremilast: A new hope in psoriasis. Ind J Clin Exp Dermatol. 2018;4(3):212-214. 